\title{
Detention time selection for stormwater quality control ponds
}

\author{
Fabian Papa, Barry J. Adams, and Yiping Guo
}

\begin{abstract}
Current stormwater quality control pond design in Ontario typically includes the specification of a uniform detention time for extended detention ponds to ensure water quality control. In reality, the pollution-control performance of such facilities is governed by two opposing forces: improved pollutant removal efficiency over longer detention times and the decreased volume of runoff captured and treated by the facility for longer detention times. The combination of these effects produces a maximum attainable level of long-term pollution-control performance at an optimal detention time. Derived probability distribution models for runoff control are used to investigate the qualitycontrol behaviour of extended detention dry ponds for the case where a design storm is specified to establish pond storage requirements and for the more general case where storage requirements may be selected on the basis of the level of control desired. Graphical relationships are developed to facilitate the planning and design process. The methodology presented encourages efficient engineering design while promoting environmental protection by ensuring a maximum level of long-term pollution control.
\end{abstract}

Key words: stormwater management, water quality, probabilistic models, optimization, stormwater ponds, detention time, pond design.

Résumé : Actuellement en Ontario, la conception d'étangs de contrôle d'eaux pluviales spécifie typiquement un temps de détention uniforme pour assurer le contrôle de la qualité de l'eau. En réalité, la performance de ces étangs de détention est gouvernée par deux forces opposées. Des temps de détention plus longs augmentent d'une part l'éfficacité du traitement et reduisent d'autre part le volume d'apport pluvial qui est capturé et traité. La combinaison de ces deux effets aboutit à un temps de détention optimal, pour lequel le niveau de contrôle de la pollution à long terme est maximal. Des modèles de distribution des probabilités pour le contrôle d'apport pluvial sont utilisés pour examiner le comportement d'étang de détention, en termes de qualité du traitement pour deux cas. Le premier cas est celui où une tempête de conception est specifié dans le but d'établir le volume de stockage nécessaire. Le deuxième cas est plus général, lorsque le volume de l'étang peut être selectioné en fonction du niveau de contrôle désiré. Des relations graphiques sont developpées pour faciliter le processus de gestion et de conception. La méthodologie presentée encourage une conception efficace tout en promouvant la protection de l'environement en assurant un niveau maximum de contrôle.

Mots clés : gestion d'eaux pluviales, qualité de l'eau, modèles probabilistes, optimisation, étangs de de contrôle d'eau pluviale, temps de détention, conception d'étangs.

[Traduit par la Rédaction]

\section{Introduction}

Stormwater quality control ponds are commonly used treatment technologies for mitigating the pollution impact of urban runoff discharged to receiving water bodies. Unlike traditional stormwater quantity (flood) control ponds, whose

Received September 3, 1997.

Revised manuscript accepted July 31, 1998.

F. Papa. Valdor Engineering Inc., 216 Chrislea Road, Suite 501, Woodbridge, ON L4L 8S5, Canada.

B.J. Adams and Y. Guo. Department of Civil Engineering, University of Toronto, 35 St. George Street, Toronto, ON M5S 1A4, Canada.

Written discussion of this article is welcomed and will be received by the Editor until July 31, 1999 (address inside front cover). function is primarily to attenuate peak flow rates, stormwater quality control ponds release treated runoff at a relatively slower rate, detaining water for longer periods to promote pollutant removal primarily through sedimentation, but also through biological uptake of nutrients and dieoff of bacteria. Extended detention dry ponds are a popular example of this technology. These ponds, as their name implies, lie empty until filled by a runoff event and are then drained at a controlled rate (or rates). The modelling of the pollutant-removal efficiency of such ponds is typically based on sedimentation theory. Additionally, if the removal of other stormwater pollutants is proportional to the removal of total suspended solids (TSS) in stormwater, which may be an acceptable assumption since many pollutants adhere to sediment particles, the modelling of TSS removal efficiency can give a reasonable indication of the overall pollution-control performance of the pond. Furthermore, since extended detention dry ponds experience continuous flow-through con- 
ditions (while there are contents in the pond) with varying inflow and outflow rates, the TSS removal efficiencies may be modelled using dynamic settling theory.

In Ontario, for stormwater discharges into a cold-water fishery, the Interim stormwater quality control guidelines for new development (MOE and MNR 1991) require that the runoff volume resulting from a $25 \mathrm{~mm}, 2 \mathrm{~h}$ rainfall be captured in a stormwater quality control pond and be detained for 12-24 h. For stormwater discharges to body-contact recreation areas, the same runoff volume requires a detention time of $72 \mathrm{~h}$. The rationale is presumably that more sensitive receivers require higher levels of treatment and that higher levels of treatment are achieved by longer detention times. The more recent Stormwater management practices planning and design manual (MOEE 1994) recommends a single, uniform detention time of $24 \mathrm{~h}$. There are dangers in accepting the specification of a uniform detention time for stormwater quality control ponds as appropriate for all cases. It is unreasonable to assume that throughout any large regional jurisdiction, a predetermined single pond detention time would provide a uniform level of pollution control everywhere due to variations in meteorology, catchment geometries, land uses, soil types, etc. Cold-water fish species are sensitive to fluctuations in water temperature, and since the temperature of stormwater management pond effluent may increase with detention time, it is desirable to keep detention time to a minimum. Furthermore, the design-storm concept is known to be fundamentally flawed for use in urban drainage system design, especially for water quality modelling problems (James 1994; Adams and Howard 1986). An understanding of the long-term impacts is required in these instances; such an understanding can only be obtained using continuous, as opposed to event or design-storm, analysis.

This paper analyzes the long-term pollution-control performance of extended detention dry ponds as a function of detention time. It is well understood that longer detention times will produce better total suspended solids (TSS) removal rates based on conventional settling theories. Although this is true in the case of discrete storm events, it may not be appropriate in the long-term performance analysis of such facilities, since as detention times increase the recovery rate of storage within the pond lessens, thereby increasing the probability of the spill of untreated stormwater runoff from a subsequent runoff event. Simultaneously, the marginal improvement in single-event TSS removal efficiency increases at a decreasing rate according to dynamic settling theory. The combination of these effects results in an optimal detention time which provides a maximum level of long-term pollution control.

A methodology is presented herein which assists the planner/engineer in making design decisions that maximize the level of pollution control attained by an extended detention dry pond by optimizing the detention time of the pond. Moreover, a pond storage volume may be easily selected on the basis of meeting a minimum required long-term pollution-control performance target. Not only will this approach benefit the environment by providing a scientifically based method to maximize the pollution-control performance of a pond design, it will also minimize the storage volume required to achieve a specified level of control resulting in reduced construction costs as well as reduced land require- ments. The methodology employs derived probability distribution models for predicting runoff quality control performance from urban drainage systems and is intended for screening-level analyses.

The seemingly simplistic approach taken in this paper arises from the present-day inability to deal with stormwater quality issues in a comprehensive, rational way. This, in turn, arises from the extremely complex nature of the underlying problem. Stormwater quality sampling results tend to be highly variable and site specific and, therefore, virtually impossible to apply with any reasonable accuracy to new developments. The approach taken herein is coherent and rational and deals directly with an important practical problem. Moreover, although the assumptions may appear to be simplistic, they are not unrealistic at this stage of development of the technology.

\section{Literature review}

Techniques developed for the prediction of the long-term pollutant-removal performance of stormwater detention ponds fall into two categories: continuous simulation modelling and statistical methods. Several deterministic models have been developed to simulate detention pond performance over extended periods of time (Ferrara and HildickSmith 1982; Hydrologic Engineering Center 1977; Medina et al. 1981a, 1981b; Nix 1982; Nix et al. 1983, 1988). An example of these deterministic models is the Storage/Treatment Block of the SWMM model (Nix et al. 1988). The principal advantage of continuous simulation models is their ability to handle a wide range of catchment hydrologichydraulic conditions and pond configurations.

Statistical methods have the advantage of predicting pond performance from the statistics of rainfall or runoff and simple representations of the catchment and the pond. Previous work on the statistical analysis of detention ponds for the control of urban runoff, or of treatment plants for the control of combined sewer overflows, includes that of Howard (1976), Chan and Bras (1979), DiToro and Small (1979), Small and DiToro (1979), Driscoll (1982, 1986), Adams and Bontje (1984), Loganathan and Delleur (1984), Loganathan et al. (1985), Segarra-Garcia and Loganathan (1992), Guo and Adams (1994), Loganathan et al. (1994), and Papa et al. (1997). Among these, the early work of Howard (1976), Chan and Bras (1979), DiToro and Small (1979), Adams and Bontje (1984), and Loganathan and Delleur (1984) concentrates on the fraction of untreated runoff volumes leaving a detention basin, and specifically deals with combined sewer overflows and wastewater treatment plants designed to treat combined sewer flows. Some of these developments can be adapted for use in the design of stormwater detention ponds. The more recent works are briefly described below.

Loganathan et al. (1985) present a method for estimating detention storage and treatment rate for a design risk (probability) of overflows from the treatment facilities into receiving waters. Segarra-Garcia and Loganathan (1992) derive a set of equations for computing stormwater detention storage capacity and treatment rate combinations as a function of pollutant-removal efficiency and relevant hydrologic statistics. Loganathan et al. (1994) present a statistical formulation for estimating the average detention time provided by a 
pond for the captured runoff. Coupled with standardized curves relating pollutant-removal efficiency to average detention time, the results of Loganathan et al. (1994) can be used to estimate the long-term pollutant-removal efficiency of stormwater detention ponds. Driscoll $(1982,1986)$ developed a probabilistic analysis methodology to compute longterm average suspended solids removal of stormwater detention ponds with permanent pools.

The approaches taken by Loganathan et al. (1985, 1994), Segarra-Garcia and Loganathan (1992), and Driscoll (1982, 1986) all start with the probability density functions of runoff, as opposed to rainfall, event characteristics. Loganathan et al. (1985, 1994) and Segarra-Garcia and Loganathan (1992) assume that the volume of a runoff event, the duration of a runoff event, and the time between successive runoff events are three statistically independent and exponentially distributed random variables. In the approach taken by Driscoll (1982, 1986) following the work of DiToro and Small (1979), runoff events are described by statistically independent gamma-distributed runoff flow rates, durations, and interevent times. A principal drawback of these approaches is that statistics of runoff from the contributing catchment must first be determined. These statistics are often unknown at the stage of planning and design of detention ponds for urbanizing areas, and vary from catchment to catchment.

Loganathan et al. (1994) demonstrate that the removal efficiency of pollutants is related to the detention time that runoff receives when routed through a detention pond. Through column settling studies (or other laboratory procedures) or simulation studies, relationships between pollutantremoval efficiency and detention time can be developed. Loganathan et al. (1994) and Schueler (1987) report such relationships where pollutant-removal efficiency is expressed as a function of detention time. Using the SWMM model, Goforth et al. (1983) analyze the performance of a detention basin by considering the capture of flows and detention of pollutants.

The definition of detention time (or residence time) most familiar to designers is given by the pond volume divided by the flow rate at which flow either enters or leaves the storage facility. This definition is applicable only when steadystate conditions prevail (i.e., constant volume and flow rates) and cannot be used directly for stormwater detention ponds because of the variable and intermittent nature of the pond inflows and outflows. Nix (1985) cautions that the detention time of runoff processed by a stormwater detention pond is much more difficult to determine than, and is quite different from, that obtained from the steady-state definition. As a result, for the design of stormwater quality control ponds, many local governments use a drawdown time (time to drain a full pond) of $24-40 \mathrm{~h}$ as a criterion, implying that equivalent detention times can be achieved. Loganathan et al. (1994) point out that drawdown time often overestimates the actual detention time received by runoff processed by detention ponds and present a statistical formulation for determining the average detention time of runoff processed by a detention pond.

In the present work, a probabilistic model is presented for the prediction of long-term average suspended solids removal for extended detention dry ponds. The inputs to the model are the meteorological parameters of the area, the hydrologic parameters of the contributing catchment, and the design parameters of the pond. For a given pond size, the detention time of the pond may be optimized to maximize runoff quality control. Alternatively, for a given level of runoff quality control, the optimal detention time and the corresponding storage volume required may be determined.

\section{Pollution-control model}

It is well understood that in order to adequately model the long-term water quality control performance of stormwater treatment facilities, continuous analysis of the drainage system is essential (e.g., Adams and Howard 1986; Gregory and James 1996; Marsalek 1978). Common technologies available to perform such analyses include continuous simulation models using long-term historical rainfall records and derived probability distribution (DPD) models that utilize statistics of meteorological event characteristics such as rainfall volume, duration, and interevent time which are derived from long-term historical rainfall records. DPD models offer the advantage of estimating the long-term runoff quality and quantity control performance of urban drainage systems using few input parameters as well as having minimal computational requirements when compared to their continuous simulation counterparts. Detailed derivations of these models have been previously documented (e.g., Adams and Bontje 1984; Adams 1996; Papa 1997).

The purpose of the present work is to develop a methodology for selecting optimal detention times of extended detention dry ponds for stormwater quality control. The DPD models, because of their mathematically compact form, are ideally suited for implementation into an optimization framework. The primary incentive for the use of such models in this application is to provide a rational method for detention time selection where the use of continuous simulation models may be unjustified from an economic and (or) engineering analysis viewpoint, particularly for planning purposes. Moreover, as a result of the relatively few input parameters required, DPD models are able to provide generalized results, whereas continuous simulation methods are best suited for site-specific applications. Comparisons of estimates for pollution-control performance of continuous simulation models and DPD models have indicated that there exists very good agreement between these different modelling techniques under practical design conditions (Adams 1996; Papa et al. 1997).

The analytical model for pollution-control performance, measured as total suspended solids (TSS) removal, for an extended detention dry pond is given by

$$
C_{\mathrm{P}}=E_{\mathrm{d}}\left\{1-\frac{\frac{\lambda}{\Omega}}{\frac{\lambda}{\Omega}+\frac{\zeta}{\phi}} \frac{\frac{\psi}{\Omega}+\frac{\zeta}{\phi} \exp \left[-\left(\frac{\psi}{\Omega}+\frac{\zeta}{\phi}\right) S_{\mathrm{A}}\right]}{\frac{\psi}{\Omega}+\frac{\zeta}{\phi}}\right\}
$$

where $C_{\mathrm{P}}$ is the fractional level of long-term pollutioncontrol performance, $S_{\mathrm{A}}(\mathrm{mm})$ is the active storage volume of the pond, $\Omega(\mathrm{mm} / \mathrm{h})$ is the controlled release rate from the pond, $\phi$ is the runoff coefficient, $\lambda\left(\mathrm{h}^{-1}\right)$ is the inverse of the 
Table 1. Settling-velocity distribution of particles in stormwater (MOEE 1994).

\begin{tabular}{lll}
\hline $\begin{array}{l}\text { Size fraction } \\
(\mathrm{mm})\end{array}$ & $\begin{array}{l}\text { \% of particle } \\
\text { mass }\end{array}$ & $\begin{array}{l}V_{\mathrm{s}} \\
(\mathrm{m} / \mathrm{h})\end{array}$ \\
\hline$\leq 20$ & 20 & 0.00914 \\
$20<x \leq 40$ & 10 & 0.0468 \\
$40<x \leq 60$ & 10 & 0.0914 \\
$60<x \leq 0.13$ & 20 & 0.457 \\
$0.13<x \leq 0.40$ & 20 & 2.13 \\
$0.40<x \leq 4.0$ & 20 & 19.8 \\
\hline
\end{tabular}

mean rainfall duration, $\psi\left(\mathrm{h}^{-1}\right)$ is the inverse of the mean rainfall interevent time, and $\zeta\left(\mathrm{mm}^{-1}\right)$ is the inverse of the mean rainfall volume (Adams 1996; Papa 1997; derived from Adams and Bontje 1984). The meteorological characteristics $\lambda, \psi$, and $\zeta$ are derived from the statistical analysis of long-term rainfall records. The volume measures expressed as depth $(\mathrm{mm})$ are implied as depth of water uniformly distributed across the total catchment area. A derivation of [1] is presented in Appendix 1. The term $E_{\mathrm{d}}$ is the overall TSS removal efficiency and is derived below.

\section{Removal efficiency}

The removal of stormwater contaminants in dry ponds takes place while there is stored water in the pond and is a function of the drawdown time of the pond. During this period of particle settling, there is flow into and (or) out of the pond. Hence, there is fluid turbulence in the pond and the particle-settling mechanism is dynamic settling. Although the present work is based on discrete particle-settling theory, modification to the removal equation could be undertaken to represent other settling mechanisms such as flocculant settling provided that reliable mathematical representations of such settling mechanisms are available.

A widely used model for the dynamic settling of discrete particles is given by

$$
\eta=1-\left(1+\frac{1}{n} \frac{V_{\mathrm{s}}}{Q / A}\right)^{-n}
$$

where $\eta$ is the dynamic settling removal efficiency; $n$ is the pond settling performance factor (or turbulence factor); $V_{\mathrm{s}}$ $(\mathrm{m} / \mathrm{h})$ is the settling velocity of the particle size of concern (specified by the user); and $Q / A(\mathrm{~m} / \mathrm{h})$ is the surface loading rate, where $Q\left(\mathrm{~m}^{3} / \mathrm{h}\right)$ is the steady-state flow-through rate of the pond, and $A\left(\mathrm{~m}^{2}\right)$ is the average surface area of the pond (Fair and Geyer 1954).

The surface loading rate can also be expressed as follows:

$$
\frac{Q}{A}=\frac{h_{\mathrm{A}}}{t_{\mathrm{s}}}
$$

where $h_{\mathrm{A}}(\mathrm{m})$ is the pond depth, and $t_{\mathrm{s}}(\mathrm{h})$ is the average detention time (under steady-state conditions) of the active storage zone. At one extreme, when the inflow rate is less than or equal to the outlet capacity and the active storage zone is empty, the detention time is zero $\left(t_{\mathrm{s}}=0\right)$. At the other extreme, when the inflow rate is greater than the outflow rate and the pond is full, the detention time is $S_{\mathrm{A}} / \Omega$.
The average detention time of stormwater in the pond is approximated by the average of these two extreme conditions according to the following expression:

$$
t_{\mathrm{s}}=\frac{1}{2} t_{\mathrm{d}}=\frac{1}{2} \frac{S_{\mathrm{A}}}{\Omega}
$$

where $t_{\mathrm{d}}(\mathrm{h})$ is the drawdown time (time to drain a full pond with no further inflow) and is defined as $S_{\mathrm{A}} / \Omega$.

Thus, [3] can be rewritten as

$$
\frac{Q}{A}=\frac{2 h_{\mathrm{A}} \Omega}{S_{\mathrm{A}}}
$$

Substituting [5] into [2] yields

[6] $\eta=1-\left(1+\frac{V_{\mathrm{s}}}{n h_{\mathrm{A}}} \frac{S_{\mathrm{A}}}{2 \Omega}\right)^{-n}$

Equation [6] applies only to a single particle size with a known settling velocity, $V_{\mathrm{s}}$. A more representative measure of pollutant-removal efficiency would consider the range of particle sizes found in stormwater. The Ontario Ministry of Environment and Energy (MOEE 1994) provides a settlingvelocity distribution based on results from the Nationwide Urban Runoff Program conducted by the U.S. Environmental Protection Agency as well as some Canadian research efforts. This distribution is used herein and is presented in Table 1.

Using a discrete particle settling velocity distribution, the overall fractional TSS removal efficiency $\left(E_{\mathrm{d}}\right)$ is given by Adams (1996) and Papa (1997):

$$
E_{\mathrm{d}}=\sum_{i} F_{i}\left\{1-\left[1+\frac{V_{\mathrm{s} i}}{n h_{\mathrm{A}}} \frac{S_{\mathrm{A}}}{2 \Omega}\right]^{-n}\right\}
$$

where $V_{\mathrm{s} i}(\mathrm{~m} / \mathrm{h})$ and $F_{i}$ are the average settling velocity and the decimal fraction of total mass contained in the $i$ th size fraction, respectively; $h_{\mathrm{A}}(\mathrm{m})$ is the pond depth; and $n$ is the turbulence or short-circuiting factor (Fair and Geyer 1954). A value of $n=3$ ("good performance") is used in the present analysis, although the user may specify an alternative value appropriate to the application. The sensitivity of the pollution-control model to the value of $n$ selected is discussed in a subsequent section.

\section{Detention time optimization}

\section{Design storm case}

To incorporate the storage volume requirements of the detention pond based on a given design storm volume and duration into the model for pollution-control performance, a set of relationships relating the pond storage $\left(S_{\mathrm{A}}\right)$ to the constant controlled release rate $(\Omega)$ and design storm characteristics is needed. The runoff hydrograph influent to the pond is approximated as a rectangular wave with an intensity equal to the average intensity of runoff $\left(i_{\mathrm{r}}\right)$ which, using linear hydrology, is given by

[8]

$$
i_{\mathrm{r}}=\frac{\phi\left(v-S_{\mathrm{d}}\right)}{d}
$$


Fig. 1. Required storage volume.

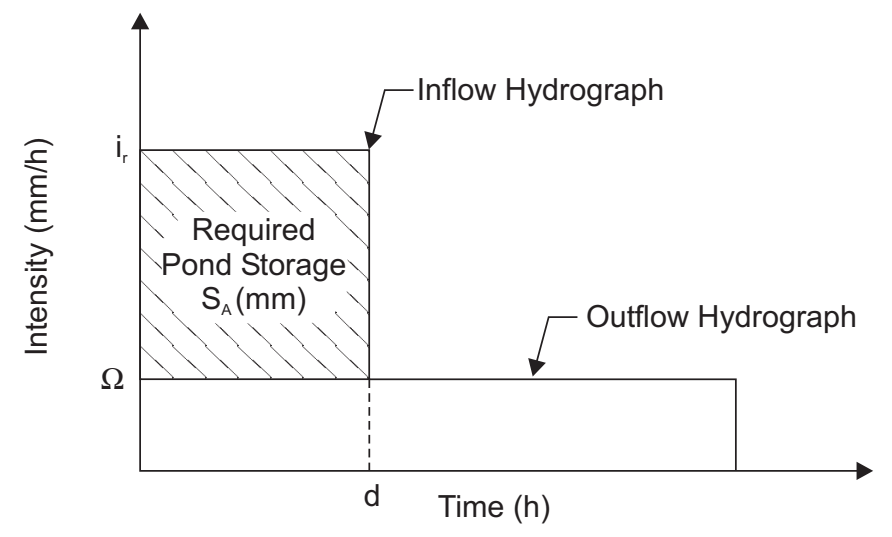

Table 2. Summary of input parameters used in the analysis.

\begin{tabular}{llll}
\hline & \multicolumn{3}{l}{ Input parameter } \\
\cline { 2 - 4 } Location & $\lambda\left(\mathrm{h}^{-1}\right)$ & $\psi\left(\mathrm{h}^{-1}\right)$ & $\zeta\left(\mathrm{mm}^{-1}\right)$ \\
\hline Toronto & 0.282 & 0.0230 & 0.200 \\
Vancouver & 0.194 & 0.0300 & 0.189 \\
Lethbridge & 0.288 & 0.0116 & 0.233 \\
\hline
\end{tabular}

where $v(\mathrm{~mm})$ is the design rainfall volume, $d(\mathrm{~h})$ is the design rainfall duration, and $S_{\mathrm{d}}(\mathrm{mm})$ is the depression storage on the catchment. Given a constant inflow hydrograph intensity and a constant controlled release rate from the pond $(\Omega)$, the storage volume required for the pond can be estimated as (see Fig. 1)

[9] $S_{\mathrm{A}}=d\left(i_{\mathrm{r}}-\Omega\right)$

Substituting [4] and [8] into [9] and simplifying yields

$$
S_{\mathrm{A}}=\frac{\phi\left(v-S_{\mathrm{d}}\right) t_{\mathrm{d}}}{t_{\mathrm{d}}+d}
$$

Equation [10] represents the required storage volume of the pond as a function of the design storm volume and duration, the catchment hydrology, and the detention time of the pond. The required controlled release rate from the pond is given by

$$
\text { [11] } \Omega=\frac{\phi\left(v-S_{\mathrm{d}}\right)}{t_{\mathrm{d}}+d}
$$

Using these expressions for $S_{\mathrm{A}}$ and $\Omega$ in the pollution-control performance model (equation [1]) yields an expression for $C_{\mathrm{P}}$ in terms of pond detention time for a given catchment, hydrologic conditions, and design storm characteristics.

To perform a numerical analysis, a test catchment was selected with a runoff coefficient $(\phi)$ of 0.5 and a depression storage $\left(S_{\mathrm{d}}\right)$ of $1 \mathrm{~mm}$. Sensitivity analyses have indicated that, using the model formulation presented herein, the pollution-control performance (in percentage terms) is independent of the runoff coefficient and is relatively insensitive to depression storage (Papa 1995). The meteorological characteristics used are those derived from the Toronto Pearson International Airport meteorological station (Adams 1996) based upon a $2 \mathrm{~h}$ interevent time definition (IETD). The
Fig. 2. Components of the pollution-control model.

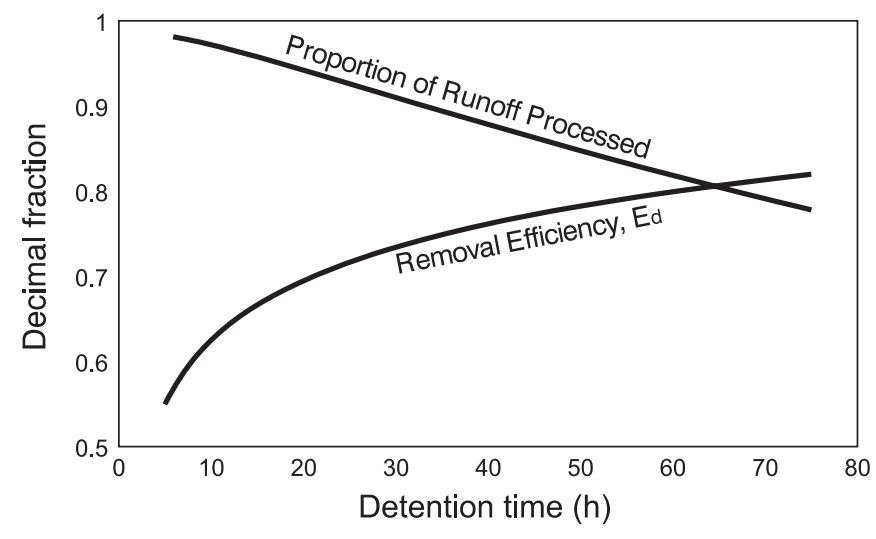

Fig. 3. Pollution-control performance of an extended detention dry pond: design-storm approach.

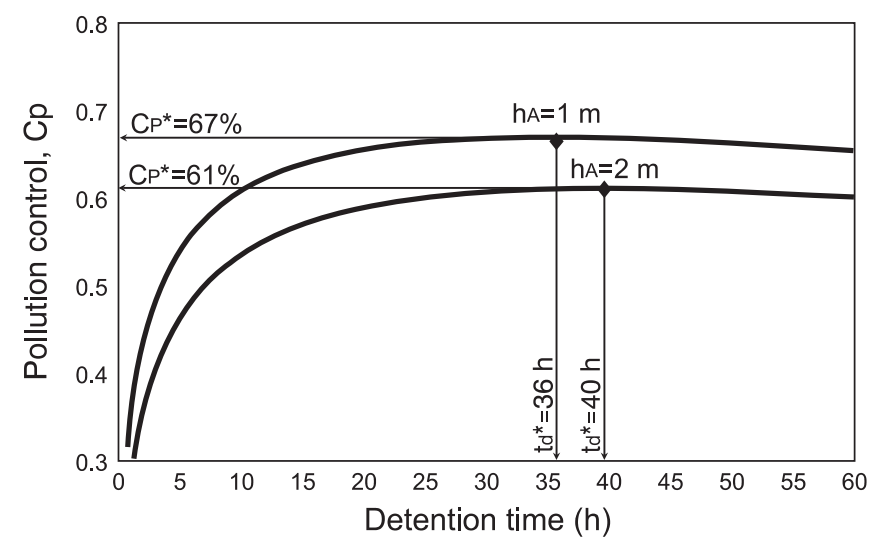

IETD is required for the statistical analysis of rainfall data and is defined as the minimum temporal spacing required between consecutive rainfall pulses to consider them as belonging to separate events. The IETD of $2 \mathrm{~h}$ has been determined to be appropriate for meteorological conditions at Toronto (Kauffman 1987). A summary of the input parameters used in the analysis is presented in Table 2.

The governing expression (equation [1]) for pollutioncontrol performance is comprised of two distinct components: the overall TSS removal efficiency $\left(E_{\mathrm{d}}\right)$ and the proportion of runoff that is processed through the pond (remainder of the expression). It is informative to investigate the behaviour of these components with respect to the detention time of the stormwater quality control pond. Note that the multiplication of these two components gives the longterm pollution-control performance achieved by the pond.

Figure 2 displays the behaviour of these two components as a function of detention time. This figure clearly indicates that an increase in the removal efficiency is experienced by the pond as detention time increases. The marginal improvement in removal efficiency, however, diminishes significantly for longer detention times. Concurrently, there is a monotonic decrease in the proportion of runoff that is actually processed through the pond, the remainder of the runoff being spilled without treatment into the receiving water. By induction, it is clear that the combination of these two effects will result in a performance curve for pollution control which contains a maximum. 
Fig. 4. Pollution-control performance of an extended detention dry pond: general approach.

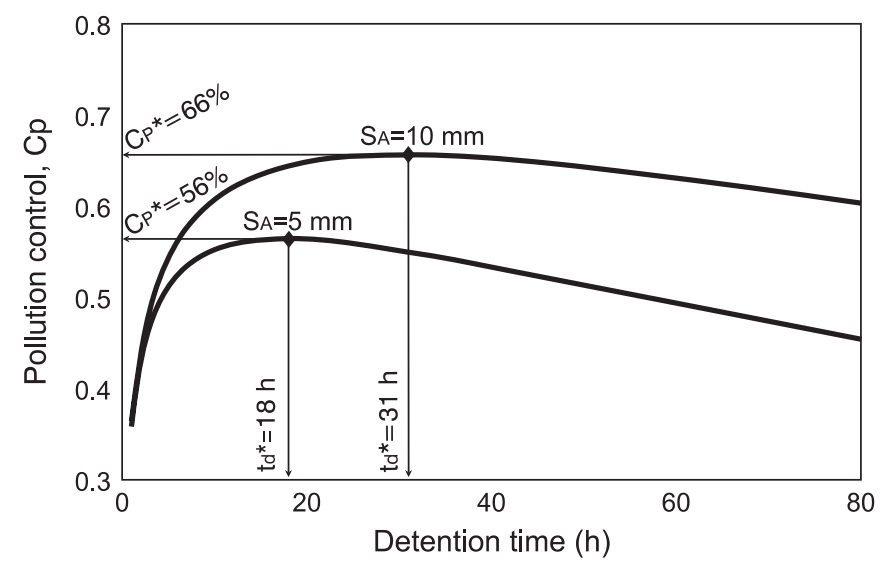

Results from the analysis of pollution-control performance with respect to detention time are displayed graphically in Fig. 3 for pond depths of 1 and $2 \mathrm{~m}$. The pollutioncontrol performance of the extended detention dry ponds designed using the design storm approach increases at a decreasing rate to a maximum, after which the performance decreases, albeit at a slow rate. The shape of the curves indicates that an increase in detention time beyond a certain level (e.g., beyond $20 \mathrm{~h}$ for the $h_{\mathrm{A}}=1 \mathrm{~m}$ curve in Fig. 3) results in a minimal improvement in pollution-control performance; hence, extremely long detention times may be counter-productive. In addition, the results presented in Fig. 3 reveal that the long-term pollution-control performance is improved as the pond depth decreases. There is, however, a practical limit to the minimum depth of a pond, since shallow ponds require more land area and may introduce performance problems as a result of the resuspension of settled pollutants. The pond depth is also an important design parameter affecting phenomena such as wave generation, temperature profiles, and the turnover of water. Although not explicitly considered herein, design features such as pond shape and the introduction of forebays, berms, and (or) baffles can be implemented to enhance pond performance.

Sensitivity analyses on the design storm parameters $(v, d)$ indicate that the pollution-control performance is relatively insensitive to the selection of design storm duration; however, it is greatly influenced by the design storm volume, as expected. Although a design storm volume of $25 \mathrm{~mm}$ results in a pond storage volume which provides a relatively good level of pollution control, a rational design methodology would select a storage volume to meet a specified pollutioncontrol objective or target.

\section{General case}

A more general approach to the design of stormwater quality control ponds provides for the selection of design parameters that meet certain pollution-control objectives. The principal design parameters of ponds are the storage volume $\left(S_{\mathrm{A}}\right)$, depth $\left(h_{\mathrm{A}}\right)$, and controlled release rate $(\Omega)$.

It is insightful to first investigate the performance of a pond with respect to detention time for a fixed storage volume and fixed depth. Figure 4 presents such an analysis for pond storage volumes of 5 and $10 \mathrm{~mm}$. This analysis em-
Fig. 5. Comparison of performances for various climates in Canada.

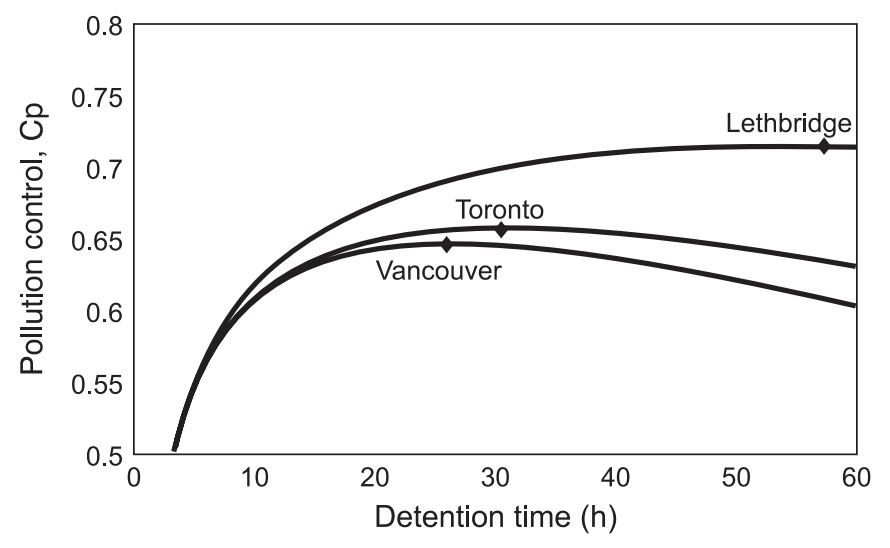

ploys the same input parameters given in Table 2 with the inclusion of a fixed pond depth of $1 \mathrm{~m}$. The results given in Fig. 4 illustrate that a maximum level of pollution-control performance exists for a given storage volume. Furthermore, both the maximum level of control and the optimal detention time increase as the storage volume increases.

Figure 5 shows the impact that different climates have on the pollution-control performance of extended detention dry ponds with a storage volume $\left(S_{\mathrm{A}}\right)$ of $10 \mathrm{~mm}$ (over the catchment area). Drier climates, such as that of Lethbridge, Alberta, which experience infrequent rainfalls (that is, the average interevent times are long) can attain relatively high performance levels, afford longer detention times as a direct result of the infrequent rainfalls, and therefore achieve a specified level of performance with a smaller storage requirement than other climates, such as that of Toronto. Climates with shorter average interevent times, such as that of Vancouver, indicate a relatively small optimal detention time, and the decrease in performance after the maximum level of control is relatively more rapid. It is, therefore, more important to determine an optimal detention time for wetter climates (i.e., those with short average interevent times).

\section{Sensitivity to settling performance factor}

Figure 6 illustrates the sensitivity of the model output to the value of the settling performance factor, $n$. In general, the variation in output is typically within a $10 \%$ range, and the model output is particularly insensitive to values of $n>$ 2. As a result of the general lack of availability of long-term stormwater quality control pond performance data, it is especially difficult to calibrate the value of $n$ with field data. Furthermore, since the value of $n$ in the model should account for aspects of the physical design of the pond, the selection of the appropriate $n$ value must be informed by engineering judgement. Of course, the pond designer should strive for a pond design which would maximize the effective value of $n$.

\section{Design graphs}

The results presented in the previous section can be extended to produce generalized design graphs which reveal information about detention time selection and maximum attainable pollution-control performance as a function of stor- 
Fig. 6. Sensitivity of model results to performance factor, $n$.

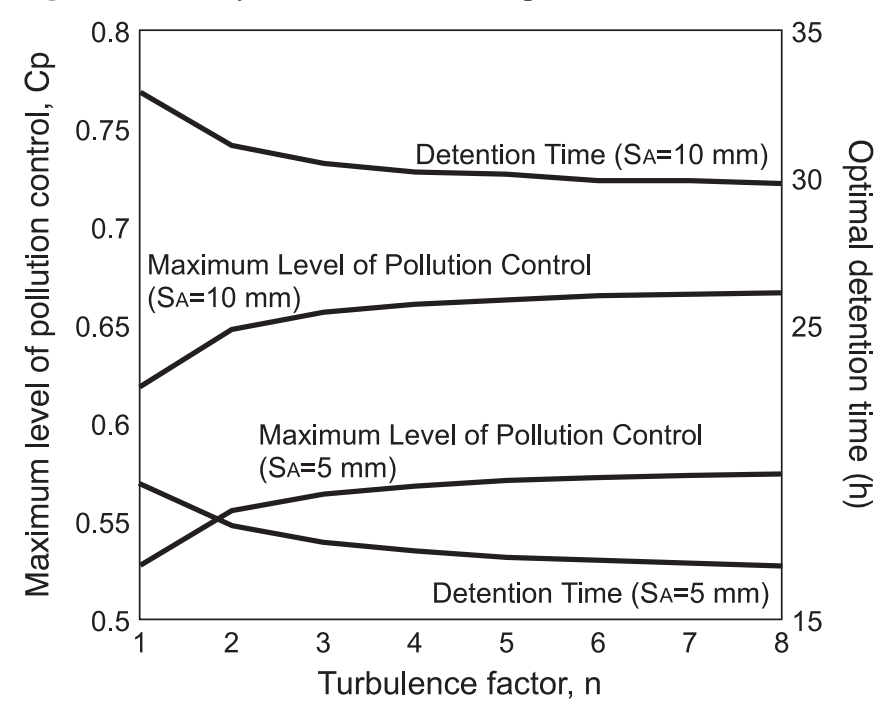

Fig. 7. Design graph relating maximum pollution control to storage volume (Toronto meteorology).

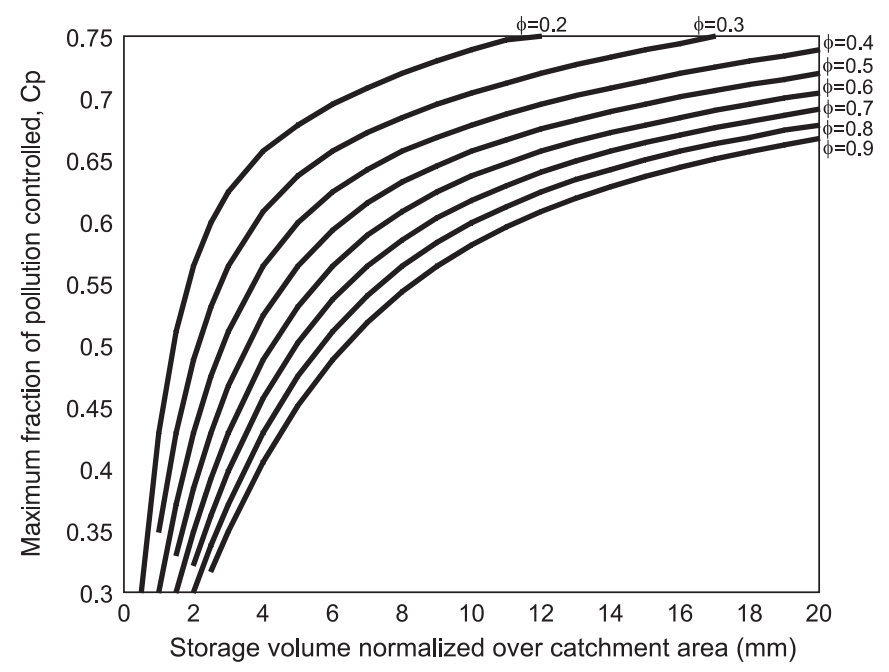

age volume. Examples of such graphs are given in Figs. 7 and 8 and are intended to be used in conjunction with each other. Figure 7 depicts the maximum attainable level of pollution-control performance of a stormwater quality control pond as a function of storage volume for a series of runoff coefficients, a pond depth of $1 \mathrm{~m}$, a depression storage of $1 \mathrm{~mm}$, the settling-velocity distribution given in Table 1, and the meteorology data given in Table 2 for the Toronto Pearson International Airport meteorological station. Figure 8 , the companion graph to Fig. 7 , indicates the optimal detention time as a function of the pond storage volume and the runoff coefficient.

The design graphs provide immediate information relating to design options and the level of pollution-control performance which may be expected from such facilities. For instance, consider the case where it is estimated that a specific storage volume can be accommodated in an urban development. By selecting the design graphs corresponding to the appropriate meteorology (i.e., geographic location) and pond depth, the engineer can obtain the optimal detention time for
Fig. 8. Design graph relating optimal detention time to storage volume (Toronto meteorology).

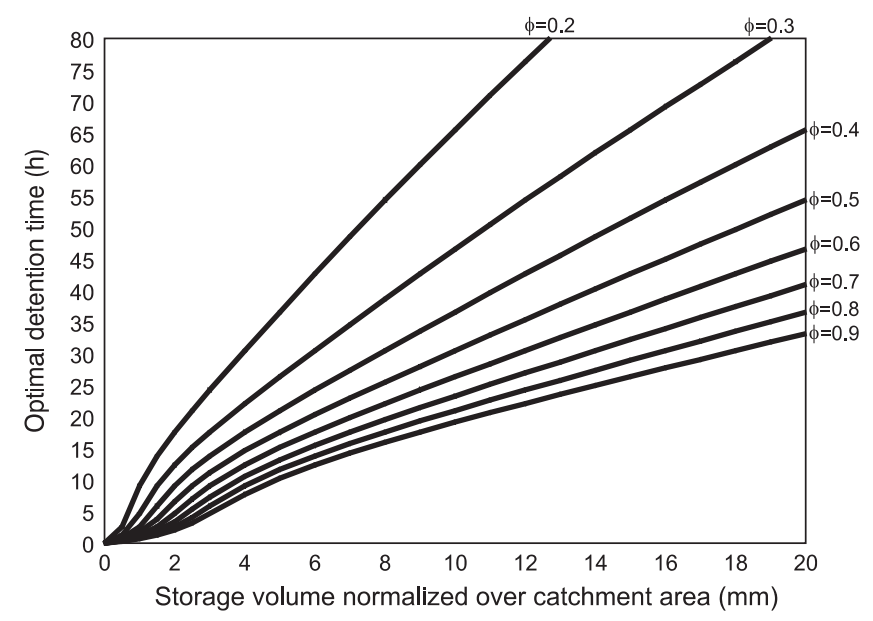

a pond of given storage volume servicing a catchment with a given runoff coefficient (Fig. 8) and estimate its long-term pollution-control performance. Alternatively, in the case that a minimum specified level of pollution-control performance is required by regulation, the engineer can determine the minimum required storage volume by scanning the required level of pollution control $\left(C_{\mathrm{P}}\right.$ in Fig. 7$)$ to identify where it intersects the curve for the appropriate runoff coefficient. The corresponding optimal detention time can then be easily obtained from Fig. 8.

\section{Summary and conclusions}

It is demonstrated that the specification of uniform detention times for extended detention dry ponds may not achieve the optimal level of pollution-control performance. A more useful approach is a rational methodology for the selection of stormwater management pond detention times and storage volumes. The analysis methodology presented herein enables the designer to select optimal detention times on a more comprehensive basis which eliminates the need to assign a uniform detention time and promotes environmental protection by maximizing the long-term pollution-control performance achieved by such facilities.

Pollution-control performance is estimated using an analytical probabilistic model expressed in a mathematically closed form which enables efficient computation thus making optimization possible with relatively little computational effort. Two parallel formulations are presented herein for pollution-control performance of an extended detention dry pond: $(i)$ the case where a volume resulting from a specified design storm (rainfall volume and duration) is to be captured by the pond, and ( $i$ i) the case where the designer is free to select the storage volume of the pond. The latter approach encourages a more rational design, since a target performance level can be met instead of passively accepting the pollution-control performance resulting from a design-storm approach.

The impact of varying meteorological conditions on the pollution-control performance of an extended detention dry pond is also investigated. Drier climates (i.e., those with relatively long dry periods between events) can achieve greater 
levels of control and afford longer detention times. For climates with frequent rain events, ponds require relatively more storage volume to achieve high levels of control. In addition, it is more important in such climates to determine optimal detention times, since unnecessarily long detention times could be counterproductive.

Design graphs have been developed to assist in the planning and design of extended detention dry ponds, which can be constructed for any climate region and can be readily available for use by municipalities, conservation authorities, and other regulatory agencies.

\section{Acknowledgments}

The authors gratefully acknowledge the financial support of this work provided by the Natural Sciences and Engineering Research Council of Canada and the University of Toronto.

\section{References}

Adams, B.J. 1996. Development of analysis methods for stormwater management with ponds. Report to the Ontario Ministry of Transportation, Toronto, Ont.

Adams, B.J., and Bontje, J.B. 1984. Microcomputer applications of analytical models for urban drainage design. In Proceedings of the Conference on Emerging Computer Techniques in Stormwater and Flood Management, October-November 1983, Niagara-on-the-Lake, Ont. American Society of Civil Engineers, New York, pp. 138-156.

Adams, B.J., and Howard, C.D.D. 1986. Pathology of design storms. Canadian Water Resources Journal, CWRA, 11(3): 4955 .

Adams, B.J., Fraser, H.G., Howard, C.D.D., and Hanafy, M.S. 1986. Meteorological data analysis for urban drainage system design. ASCE Journal of Environmental Engineering, 112(5): 827-848.

Chan, S.-O., and Bras, R.L. 1979. Urban stormwater management: distribution of flood volumes. Water Resources Research, 15 (2): $371-382$.

DiToro, D.M., and Small, M.J. 1979. Stormwater interception and storage. ASCE Journal of Environmental Engineering, 105 (EE1): 43-54.

Driscoll, E.D. 1982. Analysis of detention basins in EPA NURP program. In Proceedings of the Conference on Stormwater Detention Facilities Planning, Design, Operation and Maintenance, August 1982, New England College, Henniker, N.H., pp. 21-31.

Driscoll, E.D. 1986. Methodology for analysis of detention basins for control of urban runoff quality. Report to Office of Water, Nonpoint Source Division, U.S. Environmental Protection Agency, Washington, D.C., Report No. 440/5/87-001.

Eagleson, P.S. 1972. Dynamics of flood frequency. Water Resources Research, 8(4): 878-897.

Fair, G.M., and Geyer, J.C. 1954. Water supply and waste-water disposal. John Wiley \& Sons, Inc., New York.

Ferrara, R.A., and Hildick-Smith, A. 1982. A modeling approach for stormwater quantity and quality control via detention basins. Water Resources Bulletin, AWRA, 18(6): 975-981.

Goforth, G.F.E., Heaney, J.P., and Huber, W.C. 1983. Comparison of basin performance modelling techniques. ASCE Journal of Environmental Engineering, 109(5): 1082-1098.

Gregory, M., and James, W. 1996. Management of time-series data for long-term, continuous stormwater modeling. In Advances in modeling the management of stormwater impacts. Edited by
W. James. Computational Hydraulics International, Guelph, Ont., pp. $115-151$.

Guo, Y., and Adams, B.J. 1994. Long term performance modelling of stormwater quality ponds. In Current practices in modelling the management of stormwater impacts. Edited by W. James. Lewis Publishers, Boca Raton, Fla., pp. 99-119.

Howard, C.D.D. 1976. Theory of storage and treatment plant overflows. ASCE Journal of Environmental Engineering, 102(EE4): 709-722.

Hydrologic Engineering Center. 1977. Storage, treatment, overflow, runoff model: STORM. Generalized Computer Program 723-S8-L2520, U.S. Corps of Engineers, Davis, Calif.

James, W. 1994. Rules for responsible modelling. Computational Hydraulics International, Guelph, Ont.

Kauffman, G. 1987. A Comparison of analytical and simulation models for drainage system design: SUDS versus STORM. M.A.Sc. thesis, Department of Civil Engineering, University of Toronto, Toronto, Ont.

Loganathan, G.V., and Delleur, J.W. 1984. Effects of urbanization on frequencies of overflows and pollutant loadings from storm sewer overflows: a derived distribution approach. Water Resources Research, 20(7): 857-865.

Loganathan, G.V., Delleur, J.W., and Segarra, R.I. 1985. Planning detention storage for stormwater management. ASCE Journal of Water Resources Planning and Management, 111(4): 382-398.

Loganathan, G.V., Watkins, E.W., and Kibler, D.F. 1994. Sizing storm-water detention basins for pollutant removal. ASCE Journal of Environmental Engineering, 120(6): 1380-1399.

Marsalek, J. 1978. Synthesized and historical storms for urban drainage design. In Proceedings of the 1st International Conference on Urban Storm Drainage, University of Southampton, April 1978. Edited by P.R. Helliwell. Pentech Press Limited, London, England, pp. 87-99.

Medina, M.A., Jr., Huber, W.C., and Heaney, J.P. 1981a. Modeling stormwater storage/treatment transients: theory. ASCE Journal of Environmental Engineering, 107(EE4): 781-797.

Medina, M.A., Jr., Huber, W.C., and Heaney, J.P. 1981b. Modeling stormwater storage/treatment transients: applications. ASCE Journal of Environmental Engineering, 107(EE4): 799-816.

MOE and MNR. 1991. Interim stormwater quality control guidelines for new development. Ontario Ministry of Environment and Ministry of Natural Resources, Toronto, Ont.

MOEE. 1994. Stormwater management practices planning and design manual. Ontario Ministry of Environment and Energy, Toronto, Ont.

Nix, S.J. 1982. Analysis of storage/release systems in urban stormwater quality management. Ph.D. thesis, University of Florida at Gainesville, Gainesville, Fla.

Nix, S.J. 1985. Residence time in stormwater detention basins. ASCE Journal of Environmental Engineering, 111(1): 95-100.

Nix, S.J., Heaney, J.P., and Huber, W.C. 1983. Analysis of storage/release systems in urban stormwater quality management: a methodology. In Proceedings of the International Symposium on Urban Hydrology, Hydraulics, and Sediment Control, July 1983, University of Kentucky, Lexington, Ky., pp. 19-30.

Nix, S.J., Heaney, J.P., and Huber, W.C. 1988. Suspended solids removal in detention basins. ASCE Journal of Environmental Engineering, 114(6): 1331-1343.

Papa, F. 1995. Optimization of detention times for stormwater quality control ponds. B.A.Sc. thesis, Department of Civil Engineering, University of Toronto, Toronto, Ont.

Papa, F. 1997. Analytical probabilistic models for urban stormwater management planning. M.A.Sc. thesis, Department of Civil Engineering, University of Toronto, Toronto, Ont. 
Papa, F., Adams, B.J., and Bryant, G.J. 1997. Models for water quality control by stormwater ponds. In Advances in modeling the management of stormwater impacts. Vol. 5. Edited by W. James. Computational Hydraulics International, Guelph, Ont., pp. 1-22.

Schueler, T.B. 1987. Controlling urban runoff: a practical manual for planning and designing urban BMP's. Washington Metropolitan Water Resources Planning Board, Washington, D.C.

Segarra-Garcia, R., and Loganathan, V.G. 1992. Storm-water detention storage design under random pollutant loading. ASCE Journal of Water Resources Planning and Management, 118(5): 475-491.

Seto, M.Y.K. 1984. Comparison of alternative derived probability distribution models for stormwater management. M.A.Sc. thesis, Department of Civil Engineering, University of Toronto, Toronto, Ont.

Small, M.J., and DiToro, D.M. 1979. Stormwater treatment systems. ASCE Journal of Environmental Engineering, 105(EE3): 557-569.

\section{Appendix 1. Pollution-control performance model}

Derived probability distribution (DPD) models for urban drainage systems analysis transform probability distributions of system inputs to probability distributions of system outputs through simple mathematical representations of system hydraulics and hydrology. Inputs to an urban drainage system include the rainfall characteristics of volume, duration, and interevent time. Numerous researchers including Eagleson (1972) and Adams et al. (1986) have concluded that exponential distributions of probability density for various rainfall characteristics may be used to represent meteorological events in a probabilistic manner. The general form of the exponentially distributed probability density function (PDF) is as follows:

$$
\text { [A1] } f_{X}(x)=\gamma \mathrm{e}^{-\gamma x} ; \quad x \geq 0
$$

where $\gamma$ is the inverse of the population mean of the PDF. Using the method of moments, the population mean may be estimated by the sample mean $(\bar{x})$ determined from a statistical analysis of individual storm events.

The PDFs of rainfall volume $(v)$, duration $(t)$, and interevent time $(b)$ are given by the following expressions, respectively:

$$
\begin{array}{lll}
\text { [A2] } & f_{\mathrm{V}}(v)=\zeta \mathrm{e}^{-\zeta v} ; & v \geq 0 \\
\text { [A3] } & f_{\mathrm{T}}(t)=\lambda \mathrm{e}^{-\lambda t} ; & t \geq 0 \\
\text { [A4] } & f_{\mathrm{B}}(b)=\psi \mathrm{e}^{-\psi b} ; & b \geq 0
\end{array}
$$

where $\zeta=1 / \bar{v}, \lambda=1 / \bar{t}$, and $\psi=1 / \bar{b}$; and $\bar{v}, \bar{t}$, and $\bar{b}$ are the mean rainfall volume, duration, and interevent time, respectively.

Based on correlation analyses (e.g., Adams et al. 1986) and studies comparing continuous simulation with DPD models both with and without rainfall-characteristic dependence (Seto 1984), it is assumed that the rainfall characteristics are statistically independent. Therefore, the joint distribution of probability density may be formulated as the product of their marginal PDFs as follows:

$$
f_{\mathrm{V}, \mathrm{B}, \mathrm{T}}(v, b, t)=f_{\mathrm{V}}(v) f_{\mathrm{B}}(b) f_{\mathrm{T}}(t)=\lambda \psi \zeta \mathrm{e}^{-\lambda t-\psi b-\zeta v}
$$

A particularly useful property of storage reservoirs for estimating long-term performance is the probability of a spill occurring per rainfall event. Given an estimate of the storage contents at the end of a rainfall event, one can determine the probability of a spill occurring given the probability density functions of the rainfall characteristics discussed above and the assumptions governing the operation of the reservoir. For the purposes of planning-level analyses of urban drainage systems using DPD models, the modelling of the physical system is treated simply. The inflow hydrograph is represented by a rectangular wave using a linear hydrologic model as follows:

[A6] $\quad v_{\mathrm{r}}=\phi\left(v-S_{\mathrm{d}}\right)$

where $v_{\mathrm{r}}$ is the volume of runoff produced by a rainfall volume $v$ over a catchment characterized by a depression storage $S_{\mathrm{d}}$ and runoff coefficient $\phi$. The intensity of the square wave inflow hydrograph is estimated as the runoff volume divided by the rainfall duration $t$. The outflow hydrograph is also approximated by a rectangular wave of amplitude $\Omega$ (the controlled release rate from the pond). Although most stormwater management facilities exhibit fluctuations in inflow and outflow rates, the impact of the square wave inflow and outflow hydrographs adopted by these models is deemed to be practically acceptable, especially for quality control ponds whose outflow rates are typically very small in relation to the volume of runoff stored by the facility.

In order to derive the expression for the probability of a spill occurring from a reservoir, the spectrum of all possible conditions leading to a spill, or lack thereof, must be considered. Time histories of reservoir contents may be used to track the reservoir level, expressed as a unit depth normalized over the catchment area, as a function of time. Figures A1 and A2 illustrate the time histories of reservoir contents for deriving the probability of a spill assuming that the reservoir is full at the end of the last rainfall event, the most conservative assumption of reservoir contents which can be made.

In Figs. A1 and A2, time zero represents the end of the previous rainfall event at which time the reservoir is assumed to be full (storage $=S_{\mathrm{A}}$ ). It is assumed that the duration of the runoff event is equal to the duration of the corresponding rainfall event (duration $=t$ ). The time required to drain a full reservoir assuming no inflow is termed the drawdown time and is estimated as $S_{\mathrm{A}} / \Omega$. The time at which the next rainfall occurs is the interevent period and is denoted $b$; this event may occur when the reservoir still has contents left over from the previous event (Fig. A1) or when the reservoir is empty (Fig. A2). Table A1 summarizes the meteorological conditions required to cause a spill from the reservoir.

The probability per rainfall event of any spill occurring (i.e., $p>0$ ) is given by

[A7]

$$
\begin{aligned}
G_{\mathrm{P}}(0)=\int_{0}^{\infty}\left\{\int_{0}^{\frac{S_{\mathrm{A}}}{\Omega}} \int_{\frac{\Omega t+\Omega b}{\phi}+S_{\mathrm{d}}}^{\infty} f_{\mathrm{V}, \mathrm{B}, \mathrm{T}}(v, b, t) \mathrm{d} v \mathrm{~d} b\right. \\
\\
\left.\quad+\int_{\frac{S_{\mathrm{A}}}{\Omega}}^{\infty} \frac{\int_{\Omega t+S_{\mathrm{A}}}^{\infty}+S_{\mathrm{d}}}{\phi} f_{\mathrm{V}, \mathrm{B}, \mathrm{T}}(v, b, t) \mathrm{d} v \mathrm{~d} b\right\} \mathrm{d} t
\end{aligned}
$$


Fig. A1. Storage volume time history for reservoir not completely drained at onset of the next rainfall event $\left(b<S_{\mathrm{A}} / \Omega\right)$ resulting in spill volume $p$.

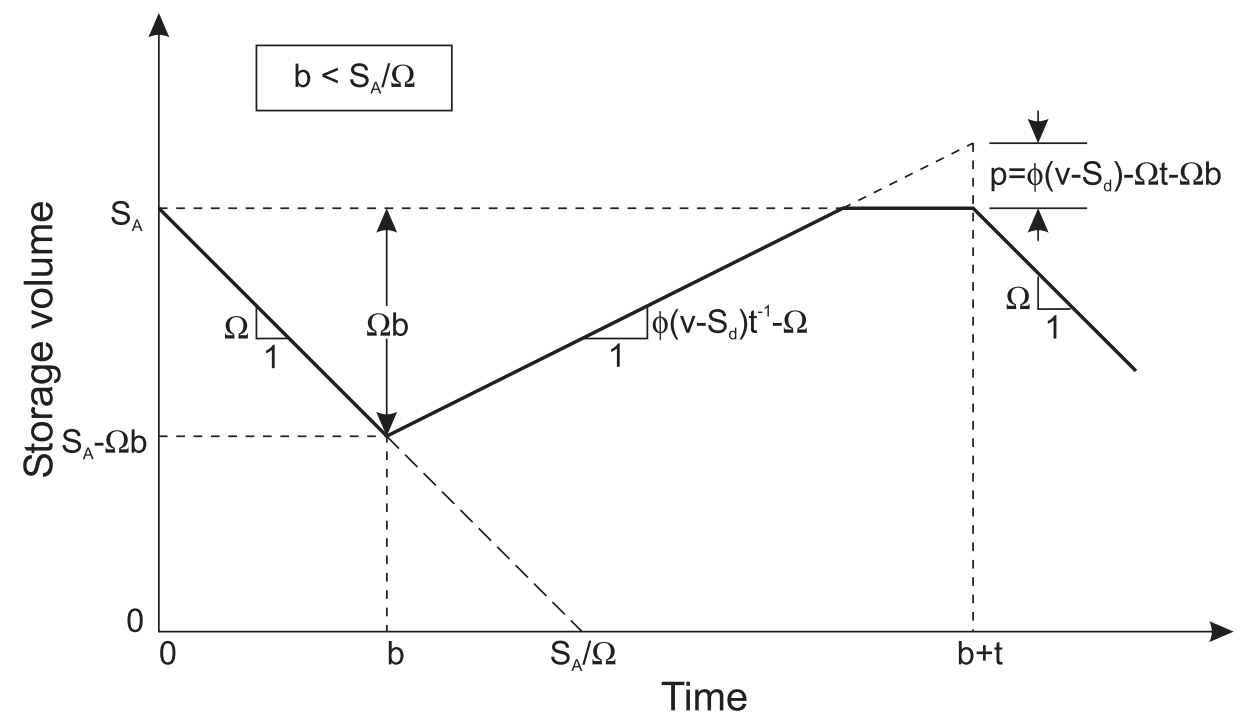

Fig. A2. Storage volume time history for reservoir empty at onset of the next rainfall event $\left(b \geq S_{\mathrm{A}} / \Omega\right)$ resulting in spill volume $p$.

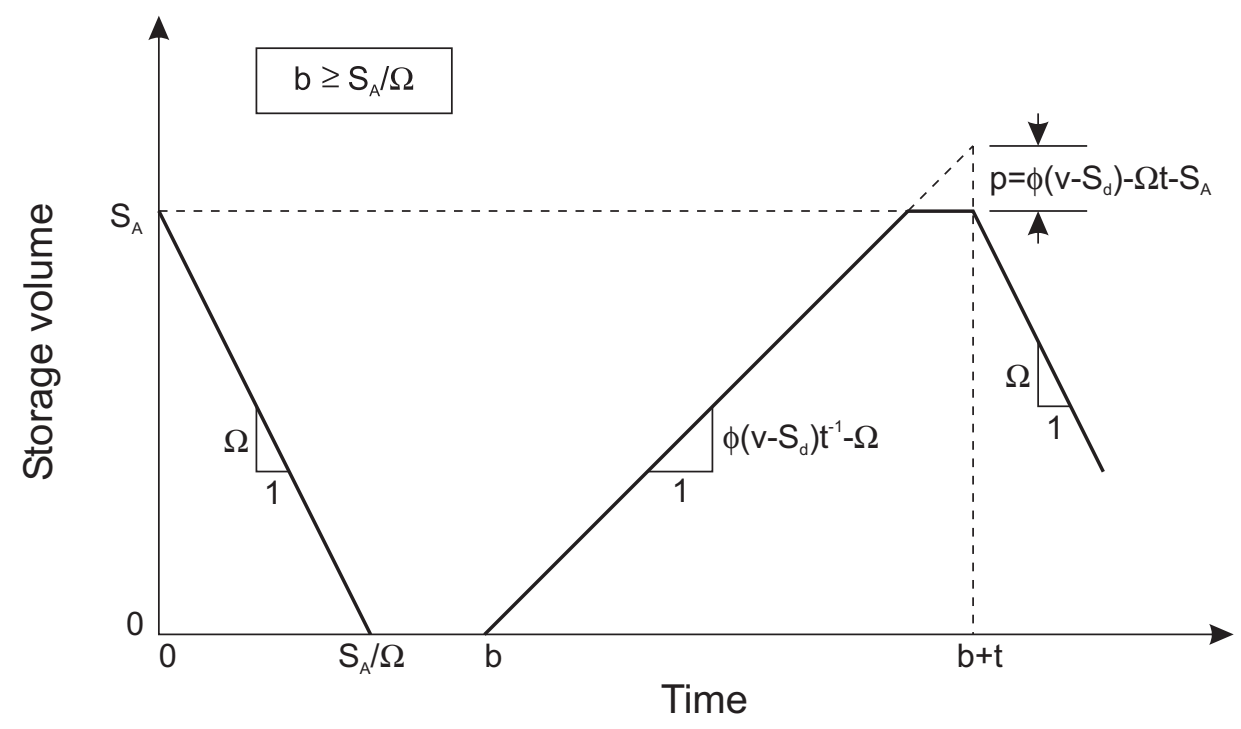

Table A1. Meteorological conditions resulting in a spill from the reservoir.

\begin{tabular}{lllll}
\hline & & \multicolumn{3}{l}{ Rainfall characteristic } \\
\cline { 3 - 5 } Case & Spill volume, $p$ & Duration & Interevent time & Volume \\
\hline$b<\frac{S_{\mathrm{A}}}{\Omega}$ & $\phi\left(v-S_{\mathrm{d}}\right)-\Omega t-\Omega b$ & $t \geq 0$ & $0 \leq b<\frac{S_{\mathrm{A}}}{\Omega}$ & $v>\frac{\Omega t+\Omega b}{\phi}+S_{\mathrm{d}}$ \\
$b \geq \frac{S_{\mathrm{A}}}{\Omega}$ & $\phi\left(v-S_{\mathrm{d}}\right)-\Omega t-S_{\mathrm{A}}$ & $t \geq 0$ & $b \geq \frac{S_{\mathrm{A}}}{\Omega}$ & $v>\frac{\Omega t+S_{\mathrm{A}}}{\phi}+S_{\mathrm{d}}$ \\
\hline
\end{tabular}

Substituting [A5] into [A7] and performing the integration yields

[A8] $G_{\mathrm{P}}(0)=\frac{\frac{\lambda}{\Omega}}{\frac{\lambda}{\Omega}+\frac{\zeta}{\phi}} \frac{\frac{\psi}{\Omega}+\frac{\zeta}{\phi} \mathrm{e}^{-\left(\frac{\psi}{\Omega}+\frac{\zeta}{\phi}\right) S_{\mathrm{A}}}}{\frac{\psi}{\Omega}+\frac{\zeta}{\phi}} \mathrm{e}^{-\zeta S_{\mathrm{d}}}$
The expected value of spill volume per rainfall event, $E[P]$, is given by the following expression (Adams and Bontje 1984; Papa 1997):

[A9] $\quad E[P]=\frac{\phi}{\zeta} G_{\mathrm{P}}(0)$

For extended detention dry ponds, it is reasonable to assume that spills receive negligible treatment, and therefore 
the average annual fraction of pollution-control performance can be estimated as the fraction of annual runoff which is processed through the pond multiplied by a treatment efficiency, viz.,

[A10] $C_{\mathrm{P}}=E_{\mathrm{d}} \frac{R-P_{\mathrm{u}}}{R}$

where $C_{\mathrm{P}}$ is the average annual fraction of pollution controlled, $R$ is the average annual volume of runoff, and $P_{\mathrm{u}}$ is the average annual volume of runoff which is spilled and is computed as the product of the expected value of spill volume per rainfall event and the average annual number of events $(\theta)$, viz.,

[A11] $P_{\mathrm{u}}=\theta E[P]=\theta \frac{\phi}{\zeta} G_{\mathrm{P}}(0)$

The average annual volume of runoff is given by (Adams and Bontje 1984; Papa 1997)

[A12] $R=\theta \frac{\phi}{\zeta} \mathrm{e}^{-\zeta S_{\mathrm{d}}}$

Substituting [8], [11], and [12] into [10] gives the following expression for pollution-control performance:

[A13]

$$
C_{\mathrm{P}}=E_{\mathrm{d}}\left\{1-\frac{\frac{\lambda}{\Omega}}{\frac{\lambda}{\Omega}+\frac{\zeta}{\phi}} \frac{\frac{\psi}{\Omega}+\frac{\zeta}{\phi} \exp \left[-\left(\frac{\psi}{\Omega}+\frac{\zeta}{\phi}\right) S_{\mathrm{A}}\right]}{\frac{\psi}{\Omega}+\frac{\zeta}{\phi}}\right\}
$$

\section{Appendix 2: List of symbols}

A: catchment area $\left(\mathrm{m}^{2}\right)$

$b$ : interevent time (h)

$\bar{b}$ : mean interevent time $(\mathrm{h})$

$C_{\mathrm{P}}$ : long-term pollution-control performance

$C_{\mathrm{P}}^{*}$ : maximum (optimal) long-term pollution-control performance

$d$ : design rainfall duration $(\mathrm{h})$
DPD: derived probability distribution

$E_{\mathrm{d}}$ : overall TSS removal efficiency

$E[P]$ : expected spill volume per rainfall event

$F_{i}$ : fraction of total mass contained in $i$ th size fraction

$G_{\mathrm{P}}(0)$ : probability per rainfall event of any spill occurring

$h_{\mathrm{A}}$ : depth of active storage zone of pond (m)

IETD: interevent time definition (h)

$i_{\mathrm{r}}$ : average runoff intensity $(\mathrm{mm} / \mathrm{h})$

$n$ : turbulence or short-circuiting factor in settling equation

$p$ : volume of spill per rainfall event normalized over catchment area $(\mathrm{mm})$

$P_{\mathrm{u}}$ : average annual volume of runoff that is spilled normalized over catchment area $(\mathrm{mm})$

PDF: probability density function

$Q$ : steady-state flow-through rate of the pond $\left(\mathrm{m}^{3} / \mathrm{h}\right)$

$R$ : average annual volume of runoff normalized over catchment area $(\mathrm{mm})$

$S_{\mathrm{A}}$ : storage volume of pond normalized over catchment area $(\mathrm{mm})$

$S_{\mathrm{d}}$ : depression storage normalized over catchment area $(\mathrm{mm})$

$t$ : rainfall duration $(\mathrm{h})$

$\bar{t}$ : mean rainfall duration $(\mathrm{h})$

$t_{\mathrm{d}}$ : drawdown time of pond $(\mathrm{h})$

$t_{\mathrm{d}}{ }^{*}$ : optimal drawdown time of pond (h)

$t_{\mathrm{s}}$ : average detention time of pond $(\mathrm{h})$

TSS: total suspended solids

$v$ : design rainfall volume $(\mathrm{mm})$

$\bar{v}$ : mean rainfall volume $(\mathrm{mm})$

$v_{\mathrm{r}}$ : volume of runoff produced by a rainfall $(\mathrm{mm})$

$V_{\mathrm{s}}$ : settling velocity $(\mathrm{m} / \mathrm{h})$

$V_{\text {si }}$ : average settling velocity of $i$ th size fraction $(\mathrm{m} / \mathrm{h})$

$\psi:$ parameter for exponential PDF of rainfall interevent time $\left(\mathrm{h}^{-1}\right)$

$\phi$ : runoff coefficient

$\gamma$ : parameter for generic exponential PDF

$\eta$ : TSS removal efficiency for a single particle size

$\lambda_{\text {: }}$ parameter for exponential PDF of rainfall duration $\left(\mathrm{h}^{-1}\right)$

$\theta$ : average annual number of rainfall events

$\zeta$ : parameter for exponential PDF of rainfall volume $\left(\mathrm{mm}^{-1}\right)$

$\Omega$ : controlled release rate from the pond normalized over catchment area $(\mathrm{mm} / \mathrm{h})$ 